\author{
Available online at https://www.rjtl.org \\ Volume: 1, Issue: 2, 44-46, 2020 \\ ISSN: 2708-3632 \\ DOI: https://doi.org/10.46590/rjtl.2020.010202
}

\title{
Analysis of Footwear Slip Resistance Property in Floor Tiles
}

\author{
Durairaj Dhanapal $^{1^{*}}$, Bahiru Melese ${ }^{2}$, Liya Shawel ${ }^{3}$ and Girum Mesfin ${ }^{4}$ \\ ${ }^{1,3 \& 4}$ Lecturer, ${ }^{2}$ Dean of Textile and Fashion Technology \\ Federal Technical and Vocational Education and Training Institute (FTVETI), Addis Ababa, Ethiopia.
}

Paper History
Received : July. 2020
Accepted : August 2020
Published: August 2020

Corresponding Author

Durairaj Dhanapal

dhanapal_d2k@yahoo.com

\begin{abstract}
Choosing slip-resistant footwear from the whole host of products on the market can be difficult. Sole descriptions are varied, from improving the grip performance to excellent multi-directional slip-resistance. Often, footwear is just described as 'slip-resistant' and the brochure do not describe the conditions for which the footwear is most suitable. Footwear selection has to take account of several factors in addition to slip resistance, such as comfort, durability and any other safety features required, such as toe protection. Accidents are expensive there are many hidden and uninsured costs. But it may be more comfortable or attractive ensuring that staff wears it and it may last longer. Specify the main surfaces and contaminants which cause slip risks in the workplace, and seek our supplier's advice on suitable footwear. Some generally slip-resistant footwear may not be suitable in specific demanding conditions. In this research, footwear are tested in water and oil conditioned floor tiles and the final result is compared with both conditions.
\end{abstract}

Keywords: Coefficient friction, Footwear, slip resistance, surface roughness, Slip tester apparatus

Citation: Durairaj Dhanapal, Bahiru Melese, Liya Shawel and Girum Mesfin. Analysis of Footwear Slip Resistance Property in Floor Tiles Research Journal of Textile and Leather, 1(2), 44-46, 2020.

\section{INTRODUCTION}

In 2016, slips, trips, and falls accounted for $27 \%$ of reported workplace injuries [1]. These incidents are detrimental to the physical well-being of the workers and expensive for the business. The National Floor Safety Institute reports that slip and fall accidents alone are the leading cause of worker compensation claims and days missed from work. For these reasons, employers often implement preventative measures such as high traction walking surfaces, fall prevention education, and slip-resistant footwear. However, there is no standardization of "slip. resistant" designations in the currently marketed shoe in the world. In shoe studies, slip risk is quantified using the coefficient of friction (COF) at the shoe-floor interface [2].

COF is calculated as the ratio of shear forces (parallel to the surface) to normal forces (perpendicular to the surface). High COF values equate to lower slip risk moments. The effects of shoe features, physical testing conditions, and flooring on COF have been investigated using mechanical slip tester's machines In 2016, Additionally, Beschorner instrument is determined the effect of mechanical slip tester parameters such as normal force reaction, sliding speed, and shoe-floor angle on $\mathrm{COF}$ measured at the interface [3]. Some CLRI research has also been done to determine the role of flooring conditions such as the type of tile and the presence of fluid contaminants. Although previous shoe-floor literature is plentiful, there is a lack of whole shoe mechanical slip testing across potentially slippery conditions for products that are currently available to consumers. Further investigation into the marketing claims associated with these shoes is also important when considering their potential to prevent slips and falling injuries.

\section{OBJECTIVES}

The purpose of this research was to quantify COF across 20 work shoes, 15 marketed as slip-resistant and 5 with no distinction, to determine variations across and within each group. Full Shoe performance was evaluated across two-fluid contaminant conditions, diluted detergent condition and water [4]. The slip resistance level of the shoe in the two contaminant conditions was determined based on how the COF value obtained compared with a standard developed by Beschorner Results. High slip resistance $(0.15 \%$ slip risk on level ground) was defined as having a COF greater than 0.30 , and moderate slip resistance (7\% slip risk on level ground) was defined as having a COF between 0.17 and 0.27 . Any shoe contaminant combinations with an average COF is less than 0.15 were considered low/non-slip resistant. Based on 
previous literature and test results, it was also expected that the detergent condition would be less slippery than the oil condition and therefore have a larger Co Efficient friction values.

\section{METHODS}

A stand-alone force plate/slip testing apparatus (Bertec, Columbus, $\mathrm{OH}$ ) was constructed for data collection purposes and a method of determining shoe-floor angle was developed. A 10-inch digital goniometer was validated against an optical measurement system with one degree of accuracy Twenty work shoes of varying styles such as Adidas, Nike, Clark's tread patterns, and slip resistance labels were selected and then evaluated using the force plate/slip tester apparatus [5]. The slip tester parameters were controlled throughout the experiment with a normal force of $250 \mathrm{~N}$, a shoe-floor angle of $17^{\circ}$, and a sliding speed of $0.5 \mathrm{~m} / \mathrm{s}$ (acceleration $5 \mathrm{~m} / \mathrm{s} 2$, deceleration $10 \mathrm{~m} / \mathrm{s} 2$ ). All shoes were tested on calibrated vinyl tile flooring in both $0.5 \%$ diluted detergent and canola oil contaminant conditions. Five trials were collected for each shoecontaminant combination for a total of 160 trials (20 shoes $\times 2$ contaminants $\times 5$ trials). The shear and normal forces for each trial were obtained from the force plate using Lab View data acquisition software and then used to calculate average COF over 200 main CLRI Lab. Finally, the average values for each model in water and oil floor conditions Slip resistance and non-slip resistance readings are noted.

\section{RESULTS AD DISCUSSION}

Slip resistance in terms of coefficient of friction (COF) for treated and normal soles was measured. The testing machine is microprocessor controlled friction test equipment, designed to measure the slip resistance of footwear. A test floor surface is located upon the carriage capable of measuring horizontal force beneath the footwear. A desired vertical force is applied to the footwear by applying pneumatic pressure. Both vertical and horizontal forces are measured using load cells. After making contact with the footwear and floor for a shorter period, static delay time, a variable speed motor draws carriage and floor surface beneath the footwear. Twoducers measure the horizontal force developed between the footwear and floor surface and the ratio of the horizontal and vertical force is displayed as $\mathrm{COF}$ on the computer screen. COF studies were made for the heel (forward slip), flat (forward slip) and forepart (backwards). Slip-resistant shoes $(0.243 \pm 0.100)$ had a higher average COF than non-slip-resistant shoes $(0.139 \pm 0.058) \quad(\mathrm{p}<0.001$, Figure 1$)$. The detergent condition $(0.280 \pm 0.093)$ had a significantly higher COF than the oil $(0.142 \pm 0.048)(\mathrm{p}<0.001)$. A high degree of variability was identified across the shoes labelled as slip-resistant as seen from the post hoc analysis. The ranking of the shoe amongst its competitors also depended on the contaminant condition. For slipresistant shoes on oil, the COF ranged from 0.096 to 0.229 , while on detergent it ranged from 0.219 to 0.436 . For non-slip resistant shoes on oil, the COF ranged from 0.080 to 0.131 , while on detergent it ranged from 0.123 to 0.266 .

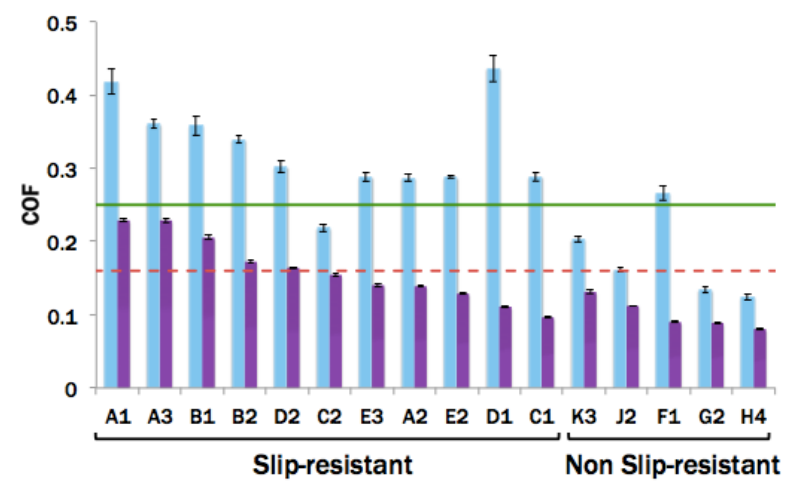

Figure 1. Several values of slip resistance and Non-Slip resistance

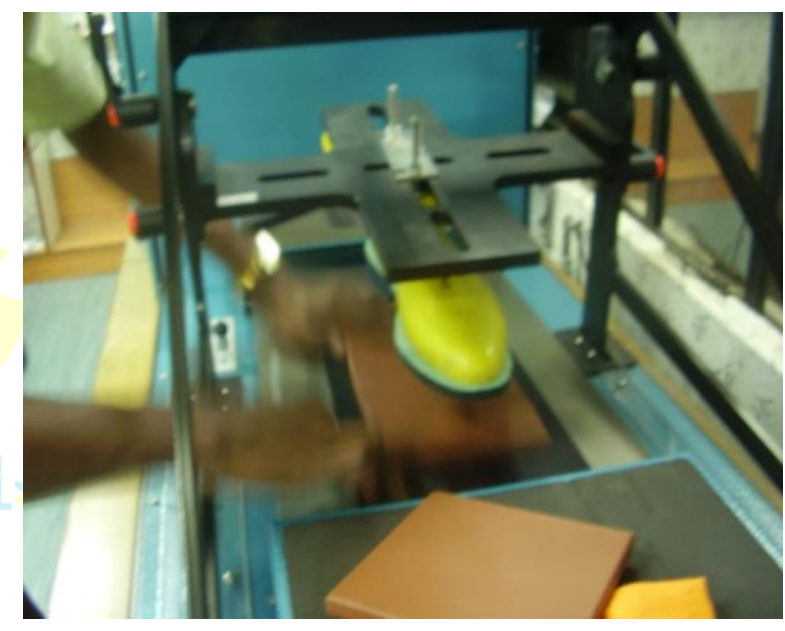

Figure 2.Slip Resistance test in oil conditioned Tiles.

Figure 1. COF for each shoe in $0.5 \%$ detergent and canola oil conditions on vinyl tile. Light blue bars represent the $0.5 \%$ detergent conditions, dark purple bars represent the canola oil condition, and the error bars depict standard deviation across 5trials. The moderate slip resistance threshold (COF $>0.16$ ) is seen in dashed red and the high slip resistance threshold $(\mathrm{COF})>$ is seen solid green. The successful development of the slip testing apparatus and data collection procedures allowed for the determination that slip-resistant shoes generally have a higher COF than non-slip resistant shoes and therefore have a decreased associated slip risk [6]. However, there was variation in the level of slip resistance within the slipresistant and non-slip resistant groups, indicating that the slip-resistant distinction is not definitive. For this reason, the criteria for slip-resistant labelling must be established. Five out of the 15 shoes marketed as slipresistant statistically outperformed the best non-slip resistant shoe, so selecting one of these five shoes as a 
preventative measure for slip and fall incidents would provide a clear reduction in slip risk and likely benefit the consumer [7]. The reported differences in shoe slip resistance across contaminant conditions will allow employers to select an appropriate shoe based on the contaminant most frequently encountered in their business [8]. Also, the increased slip risk associated with canola oil indicates the importance of limiting spills and access to such substances in the workplace.

Further research should be completed on these and similar work shoes to determine how they perform on other tiles such as porcelain and quarry tile as well as how they perform in other contaminant conditions such as water [9]. An analysis of a shoe tread pattern and style would also be beneficial when considering new shoe design. Because this study was limited to a mechanical testing apparatus, the results should be validated using human subjects testing next, ultimately leading to slip prevention in the workplace [10].

\section{CONCLUSIONS}

Due to the lack of static friction force in contact footwear-floor is often the reason for falls and injuries it is necessary to pay more attention to footwear and floor production in part of tribological properties. A successful development of the slip testing apparatus and data collection procedures allowed for the determination that slip-resistant shoes generally have a higher COF than non-slip resistant shoes and therefore have a decreased associated slip risk. However, there was variation in the level of slip resistance within the slip-resistant and non-slip resistant groups, indicating that the slip-resistant distinction is not definitive. For this reason, the criteria for slip-resistant labelling must be established. Five out of the 20 shoes marketed as slip-resistant statistically outperformed the best nonslip resistant shoe, so selecting one of these five shoes as a preventative measure for slip and fall incidents would provide a clear reduction in slip risk and likely benefit the consumer. The coefficient of friction measures the resistance between the walkway surface and shoe sole material moving over it. The machine can be set to test under try, wet or with contaminant conditions with a specific requirement. The reported differences in shoe slip resistance across contaminant conditions will allow employers to select an appropriate shoe based on the contaminant most frequently encountered in their business. In that sense measurement of the static friction coefficient between footwear sole and floor tiles, samples were performed. For that purpose, it was designed measuring device for static friction estimation. Measuring results show that the static friction coefficient is stochastic and unpredictable. Some samples should be industrial shoes and floors, tiles on public walkways, white stripes on pedestrian crosses the street and material other risky points where falls and accidents can happen. An analysis of a shoe tread pattern and style would also be beneficial when considering new shoe design. Because this research was limited to a mechanical testing apparatus, the results should be validated using human subjects testing next, ultimately leading to slip prevention in the workplace.

\section{REFERENCES}

[1]. Chang, W.R., The effect of surface roughness and contaminates on the dynamic friction between porcelain tile and vulcanized rubber. Safety of Science. 2002: 40, 577-591.

[2]. Manning, D.P. and Jones, C. The superior slipresistance footwear soling compound T66/103, Safety Science, 1994, 18:45-60.

[3]. Hirvonen, M., and Gronqvist, R. 1998, Influence of wear on footwear soles in slip resistance assessment, Proceedings ofInternational Fall Protection Symposium \& Exhibition, September 15-18, 1998, Germany, 108-109.

[4]. Bentley T. Tappin D, Moore D, Legg S, Ashby L, ParkerR. Investigating slips, trips, and falls in the NewZealand dairy farming sector, Ergonomics 2005, 48:1008-19.

[5]. Owens D.K.Wendt R.C.: Estimation of the surface free energy of polymers. Journal of Applied Polymer Science. 13:1741-1747 (1969).

[6]. Ann E. Fendley, M.D. and Howard P. Medoff, Ph.D., P.E. Required coefficient of friction versus top-piece/outsole hardness and walking speed: the significance of correlations, Journal Forensic Science 1996, 41 (5): 763-769.

[7]. Wilson, M.P., "Development of SATRA Slip Test and read Pattern Design Guidelines, "Slips, Stumbles, and Falls; Pedestrian Footwear and Surface, ASTM STP 1103. B.E.Gray, Ed., American Society for Testing and Materials, 1990,113-123.

[8]. Tabor, D. 1974, Friction, adhesion and boundary lubrication of polymers, in L-H. Lec (ed.), Advances in Polymer Friction and Wear, Polymer Science and Technology, Vol. 5A (New York: Plenum Press), 5- 30.

[9]. R.ohae Myung and James L. Smith The effect of load-carrying and floor contaminants on slip and fall parameters, Ergonomics, (1997). 40: 2, 235-246.

[10]. SATRA TM 144: 2007. Friction (Slip Resistance) of footwear and flooring. SATRA Technology Centre, UK. 